Educational Guidance and Counseling Development Jounal p-ISSN:2615-3661 | e-ISSN: 2615-8358

Vol. 1, No. 1, April 2018, 6 - 15

\title{
MEWASPADAI MISKONSEPSI NILAI BUDAYA DALAM PELAKSANAAN KONSELING INDIVIDUAL
}

\author{
Amirah Diniaty ${ }^{1}$ \\ ${ }^{1}$ Menagemen Pendidikan Islam, Universitas Islam Negeri Sultan Syarif Kasim Riau \\ e-mail: Amirah.diniaty@gmail.com
}

\begin{abstract}
ABSTRAK. Cultural differences between clients and counselors will be an obstacle to effective counseling if counselors are not aware of misconceptions and misunderstanding of the client's cultural values. The purpose of this study is to describe the form of misconception of cultural values that must be wary of the counselor and the action that should be done by the counselor in order to avoid the misconception of cultural values while doing the counseling process. This research type is library research with qualitative approach. The misconceptions experienced by the counselor may be culturally encapsulated, overculturalizing, racism and client acculturation processes. Counselors need to understand and have sufficient cultural insight and learn about their relevance to client behavior. One model of cross-cultural perspective that counselors can use in preventing the misconception of cultural values is the McFadden model. This model emphasizes the need for a counselor to master the client's cultural knowledge, to understand ethnic, racial, performance, conversation, social group behavior from clients in order to have meaningful communication, and appropriate counseling approaches.
\end{abstract}

Kata kunci: wary, misconception, cultural value, individual counseling

\section{PENDAHULUAN}

Manusia adalah makhluk berbudaya yang diwariskan turun temurun dari nenek moyangnya. Cohen, (dalam Gladding 2012:99) menegaskan adanya budaya akan membentuk perilaku, pemikiran, persepsi, nilai, tujuan, moral dan proses kognitif manusia. Itu terjadi secara disadari maupun tidak disadari. Oleh sebab itu disadari atau tidak, budaya menjadi salah satu penentu peradaban kehidupan manusia sehingga terjadi perkembangan ke arah yang lebih baik.

Makna budaya secara inklusif dan luas menurut Axelson (1999) adalah sekelompok orang yang mengidentifikasi atau berasosiasi satu dengan yang lain berdasarkan kesamaan tujuan, kebutuhan, atau latar belakang. Artinya budaya dapat terbentuk pada satu komunitas kehidupan dimasyarakat yang memiliki kesamaan dan mungkin akan berbeda dengan budaya pada komunitas masyarakat lainnya.

Konsepsi yang dipahami tentang manusia sebagai makhluk berbudaya ditegaskan oleh Vacc, Nicholas A(2003); "individuals are products of their culture and experience and cannot be considered apart from the systems in which theyparticipate. Konsep seperti ini akan mewarnai bagaimana interaksi antar manusia apalagi mereka berbeda budaya.

Perbedaan budaya antar orang jelas akan memberi pengaruh terhadap efektifitas interaksi sosial yang terjadi diantara mereka apalagi itu menyangkut hubungan profesional seperti konseling. Lebih ditegaskan lagi, interaksi atau hubungan antara pelaksana kegiatan konseling 
yang disebut konselor dengan orang yang dikonselinginya disebut klien, akan sangat diwarnai oleh budaya mereka masing-masing. Hasil penelitian Sue \& Sue (dalam Gladding, 2012:98) menemukan bahwa 50\% klien dari budaya minoritas berhenti setelah 1 sesi konseling, dibandingkan dengan sekitar 30\% klien dari budaya mayoritas. Hal ini menunjukkan bahwa klien dari budaya minoritas menemukan pengalaman konseling yang tidak menyenangkan.

Pada kenyataannya selalu terdapat perbedaan dan keunikan individu dalam kehidupan klien dan konselor. Secara sederhana, berbeda jenis kelamin antara konselor dan klien, perbedaan bahasa, kebiasaan, kepercayaan, agama dan lokasi tempat tinggal, semua menjadi bagian dari cerita budaya yang dianut seseorang. Faktanya juga bahwa setiap orang menginginkan untuk diterima dan diakui keunikan atau ciri khas diri mereka masing-masing. Mereka juga tidak mau terlihat aneh, dan ingin dipahami oleh orang lain. Dalam hal ini konselor menurut Vacc, Nicholas A (2003:6 ) haruslah membantu klien untuk dapat melewati badai dalam kehidupannya:

The fact that although all people desire acceptance, they also enjoy their uniqueness. In many cases they do not want to be mainstreamed, to develop middle-class values, or to lose their individuality and dignity. They prefer that their difficulties and differences be understood rather than interpreted and evaluated Savy counselors are not concerned with the shoulds, They are concerned with helping the individual navigate the storms of life.

Hubungan konselor dan klien dalam proses konseling individual adalah hubungan profesional yang terikat oleh kepentingan utama yaitu kemaslahatan klien. Terkait dengan itu keefektifan konseling yang dilaksanakan konselor guna mengentaskan masalah klien menurut Gladding (2012:98) bergantung pada salah satu faktor terpenting yaitu relasi satu sama lain, dan saling mengertinya antara konselor dan klien. Hal itu lebih mudah dicapai apabila terdapat kesamaan budaya diantara mereka. Sebagai tenaga profesional, konselor dituntut untuk lebih mewaspadai terjadinya miskonsepsi tentang budaya klien yang akan berpengaruh pada pelaksanaan konseling yang diselenggarakan. Ridley (2005 dalam Gladding, 2012) menegaskan setiap kendala yang muncul dalam proses konseling yang mengandung multikultural isu harus diwaspadai dan dikenali, dimengerti dan diselesaikan dengan penuh empati jika konselor ingin bekerja efektif dengan klien yang berbeda dengan mereka.

Berdasarkan alasan di atas, perlu dijabarkan dan dijawab pertanyaan tentang bagaimana bentuk miskonsepsi nilai budaya yang harus diwaspadai oleh konselor? Apa yang seharusnya dilakukan konselor agar tidak terjadi miskonsepsi nilai budaya saat melakukan proses konseling? Jawaban terhadap pertanyaan di atas, menjadi isi dari tulisan ini yang diperoleh melalui metode studi kepustakaan. Penulis mengumpulkan dari berbagai referensi yang kemudian diramu dalam bentuk sintesa sebagai jawaban terhadap pertanyaan tersebut.

Seorang konselor bisa mewaspadai miskonsepsi nilai budaya klien adalah tuntutan di era globalisasi dimana ketersediaan media komunikasi seperti telepon, televisi, email, fax machines, computer, radio dan alat transportasi seperti pesawat terbang akan memberikan kemudahan bagi setiap orang untuk bertemu dengan persoalan budaya yang berbeda. . James Fuller (dalam Vacc, Nicholas A, 2003) menegaskan "Countries and peoples are not operating in isolation", sehingga dapat diprediksi kedepannya akan banyak pembawuran budaya dan terjadi shock culture bagi individu yang tidak siap sehingga ia akan memerlukan konseling.

Kewaspadaan konselor ini dalam kondisi Indonesia sebagai salah satu negara ASEAN, telah disepakati bersama sejak tahun 2015, yaitu MEA (masyakat ekonomi ASEAN) bahwa arus barang dan jasa, memungkinkan terjadinya benturan budaya antar penduduk pendatang dan pribumi. Hal ini menjadi sebuah peluang diperlukannya oleh klien konseling lintas budaya. Terjawabnya pertanyaan tersebut dapat menjadi rambu-rambu bagi konselor agar miskonsepsi nilai budaya, tidak terjadi dalam proses konseling. 


\section{KAJIAN LITERATUR}

\section{Hakekat Budaya dan Multikultural}

Dalam psikologi lintas budaya, budaya telah dideskripsikan sebagai sebuah fuzzy set karena tidak adanya kesepakatan dalam defenisi, konseptualisasi dan operasionalisasi (Rohner, 1984, Triandis, 1980 dalam Uichol Kim, 2010: 16). Kata Budaya berasal dari bahasa latin cultura, yang berarti sampai atau mengolah/membudidayakan. Taylor (1971dalam Uichol Kim, 2010: 16) mendefenisikan budaya sebagai "keseluruhan yang kompleks yang di dalamnya termasuk pengetahuan, keyakinan, seni, moral, hukum, adat-istiadat, dan semua kapabilitas serta kebiasaan lain yag didapat sebagai anggota masyarakat. Selain itu Herkovits (1955dalam Uichol Kim, 2010: 16) menegaskan budaya adalah bagian buatan-manusia dari lingkungan.

Lebih lanjut dapat dilihat variabel yang ada dalam kata budaya, sebagaimana dijelaskan Pederson (dalam Gladding, 2012:99) meliputi; (a) variabel etnografik seperti etnisitas, kewarganegaraan, agama dan bahasa, (b) variabel demografik dari umur, gender, tempat tinggal, (c) variabel status seperti latar belakang ekonomi, sosial, pendidikan dan afiliasi atau keanggotaan formal atau informal dalam cakupan yang lebih luas.

Antroplog Beattie menyimpulkan bahwa kebudayaan mencakup semua tingkah laku yang dipelajari manusia (cultural behavior) yang bukan hasil insting (Martin,2007:42), tetapi hasil belajar warga dari warga lain sehingga memungkin ia diteriam sebagai warga masyarakat itu. Dengan berbekal tingkah laku kultural (Ross,1963:85) itu, warga bisa berfungsi dan bertingkah laku dengan baik di masyarakat.

Moh Ansyar (2014) menegaskan seseorang yang hidup terpisah dari kelompoknya tidak akan memperoleh pengetahuan, keterampilan atau tingkah laku kultural lain sebagai bagian dari nilai-nilai budaya masyarakatnya. Dia hanya mengandalkan pengalaman sendiri tentang cara pemecahan masalah yang dihadapinya tanpa mengambil manfaat dari pengalaman generasi sebelumnya. Oleh sebab itu, hanya dengan hidup bersama di masyarakat seorang individu dapat mempelajari kekayaan budaya sosial dan tingkah laku budayanya. Kekayaan inilah yang dapat membuat seorang individu menjadi manusia berbudaya sehingga manusia disebut 'binatang berbudaya" (Broom\&Selznich, 1963:52).

Lebih jauh dijelaskan Smith, Stanley \& Shores (1957 dalam Moh.Ansyar, 2014) bahwa walaupun masyarakat dan kebudayaan adalah dua hal yang berbeda, tetapi tanpa kebudayaan tidak ada masyarakat, dan tanpa masyarakat tidak ada kebudayaan. Keterkaitan yang erat antara budaya dan masyarakat menimbulkan perbedaan budaya antara satu masyarakat dengan masyarakat lain. Hasil budaya masyarakat merupakan suatu keperibadian yang juga suatu kekuatan masyarakat itu sehingga perlu dipelihara, dikembangkan dan diwariskan kepada generasi berikut.

Arti penting budaya dalam kehidupan manusia ditegaskan oleh dalam Uichol Kim, 2010: 18) bahwa tanpa budaya manusia aa seperti binatang lainnya menyusut sampai ke insting-insting dasar. Budaya menjadikan manusia mampu berpikir, merasakan, berperilaku seperti manusia. Budayalah yang memungkinkan manusia tau dengan dirinya, merasakan kebermaknaan hidupnya, berkomunikasi dengan orang lain dan mengelola lingkungannya. Sheweder (1991 dalam Uichol Kim, 2010: 17) menegaskan karena manusia berbudaya maka ia bisa berperilaku dan mengelola realita. Alat indra yang kita miliki dapat mengenali dunia luar melalui budaya yang dimiliki masingmasing orang.

Dalam implementasinya menurut Sheweder (1991 dalam Uichol Kim, 2010: 17) seringkali kita terjebak, apapun yang kita lakukan sebenarnya berdasarkan budaya yang kita miliki, namun kita tidak bisa menjelaskan apa budaya yang kita punya. Inilah yang menimbulkan masalah sehingga perlu pembelajaran tentang budaya bagi manusia. Sebuah budaya juga identik dengan istilah multikultural. Locke (1998 dalam Gladding 2012:99) menjelaskan fokus yang paling 
mencolok dari kata multikulturalisme adalah keunikan dan konsep kelompok yang terpisah yang memfasilitasi perhatian pada perbedaan individual.

\section{Konseling Individual Yang Lintas Budaya}

\section{Penyelenggaraan Konseling Individual}

Konseling individual merupakan suatu pertalian timbal balik antara dua orang individu yaitu satu konselor membantu satu orang lain (conselee) supaya ia lebih baik memahami dirinya dalam hubungannya dengan masalah-masalah hidup yang dihadapinya pada waktu itu dan waktu yang akan datang (James Adam dalam Syahril dan Riska Ahmad (1986 ). Gustad's (dalam Gibson, 1995) menyebutkan hakekat konseling sebagai berikut:

Counseling is a learning-oriented process, carried on in a simple, one-to-one social environment, in which a counselor, professionally competent in relevant psychological skill and knowledge, seeks to assist the client, by methods appropriate to the latter's needs and within the context of the total personnel program, to learn more about bimself and to accept bimself, to learn how to put such understanding into effect in relation to more clearly perceived, realisticaly defined goals to the end that the client may become a happier and more productive member of his society.

Ethical Standard of American Personnel and Guidance Association (dalam Belkin (1975) menyebutkan bahwa: "A counseling relationship denotes that the persons seeking belp retain full freedom of choice and decision and that the helping person has no authority or responsibility to approve or disapprove of the choices or decisions of the counselee or client'. Hubungan konseling adalah sebuah hubungan yang membantu klien dalam membuat pilihan dan keputusan.

Sementara itu, Gibson \& Mitchell (1995) menyatakan definisi konseling perorangan sebagai berikut: "Individual counseling is a one-to-one relationship involving a trained counselor and focuses on some aspects of a client's adjusment, developmental, or decision-making needs. This process provides a relationship and communications base from which the client can develop understanding, explore possibilities, and initiate change.

Sejalan dengan itu pendapat Dryden (dalam Palmer, 1989); bahwa konseling perorangan sangat menjaga kerahasiaan klien; konseling perorangan akan membuat hubungan akrab antara klien dan konselor; konseling perorangan sebagai proses pembelajaran klien; konseling perorangan adalah sebuah proses teraputik. Lebih lanjut, disimpulkan bahwa konseling perorangan membantu klien yang ingin membuat perbedaan dirinya dengan yang lain. Konseling perorangan juga akan sangat membantu konselor dalam membuat variasi gaya teraputik untuk klien yang berbeda. Konseling perorangan menurut Prayitno dan Erman Amti (2004) adalah "proses pemberian bantuan yang dilakukan melalui wawancara konseling oleh seorang ahli (disebut konselor) kepada individu yang sedang mengalami sesuatu masalah (disebut klien) yang bermuara pada teratasinya masalah yang dihadapi klien".

Konseling individual bertujuan terentaskannya masalah yang dialami klien. Masalah klien dimaksud memiliki ciri-ciri; sesuatu yang tidak disukai adanya, sesuatu yang ingin dihilangkan dan sesuatu yang dapat menghambat atau merugikan. Jadi tujuan umum konseling individual mengentaskan masalah klien adalah mengurangi intensitas ketidaksukaan atas keberadaan sesuatu yang dimaksud/meniadakan keberadaan sesuatu, mengurangi intensitas hambatan/kerugian yang ditimbulkan oleh sesuatu yang dimaksud. Fungsi utama yang konseling individual ini adalah fungsi pengentasan. 
Prayitno (2004) menjelaskan adapun tujuan khusus konseling individual adalah (1) memahami seluk-beluk masalah yang dialami secara mendalam dan komprehensif serta positif dan dinamis (fungsi pemahaman) (2) dikembangkannya persepsi dan sikap serta kegiatan demi terentaskannya secara spesifik masalah yang dialami klien (fungsi pengentasan) dan (3) pengembangan dan pemeliharaan potensi klien dan berbagai unsur positif yang ada pada dirinya (fungsi pengembangan/pemeliharaan). Secara khusus konseling individual juga bertujuan untuk (4) menyiapkan klien untuk memiliki kekuatan bagi tercegah menjalarnya masalah yang sekarang sedang dialami dan tercegahnya masalah-masalah baru (fungsi pencegahan). Terakhir (5) konseling individual juga membentuk kemampuan klien untuk membela diri sendiri menghadapi keteraniayaan (fungsi advokasi).

Komponen konseling individual adalah konselor dan klien. Konselor adalah seorang ahli dalam bidang konseling yang memiliki kewenangan dan mandat secara profesional untuk melaksanakan kegiatan pelayanan konseling. Klien adalah seorang individu yang sedang mengalami masalah atau setidak-tidaknya sedang mengalami sesuatu yang ingin ia sampaikan kepada orang lain. Secara menyeluruh dan umum proses layanan konseling individual terentangkan dari kegiatan paling awal sampai akhir yaitu lima tahap: 1). pengantaran2). Penjajakan3). Penafsiran, 4). Pembinaan, 5). Penilaian. Diantara kelima tahap itu tidak ada batas yang jelas, bahkan kelimanya cenderung sangat bertumpang tindih.

Klien datang/menemui konselor dengan cara yang berbeda-beda. Ada yang datang sendiri dengan kemampuan yang kuat untuk memenuhi konselor (self referal) ada yang datangan dengan perantara orang lain bahkan ada yang terpaksa karena didorong oleh pihak tertentu seperti orang tua. Kedatangan atau pertemuan klien dengan konselor dilatarbelakangi oleh kondisi tertentu yang ada pada diri klien. Menyikapi hal itu konselor memiliki prinsip KLIEN TIDAK PERNAH SALAH (KTPS). Lebih lanjut menurut Prayitno (2004) keefektifan konseling individual mengikuti tahapan berikut :

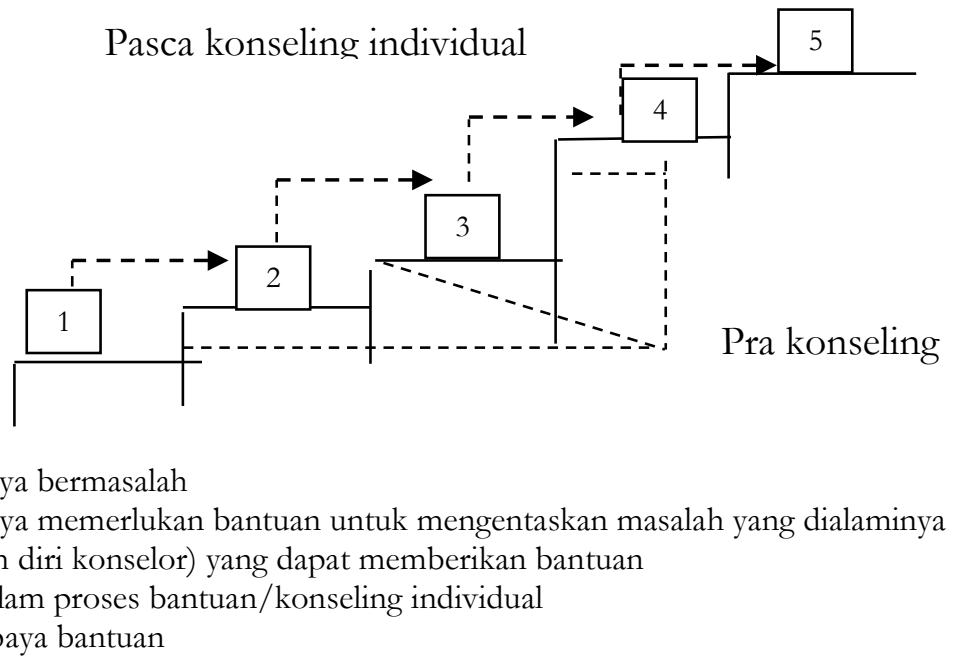

Konseling perorangan sebagai sebuah kegiatan pelayanan profesional menurut Prayitno (1994) harus memenuhi etika; yaitu kerahasiaan, keterbukaan dan tanggung jawab serrta penekanan keputusan diambil oleh klien sendiri. Penjelasan tentang proses konseling individual yang terakhir yang perlu dipahami adalah penggunaan teknik. W.S Winkel (1985) menjelaskan; Selama wawancara konselor menggunakan berbagai teknik. konseling yaitu reaksi atau jawaban tertentu dari pibak konselor. Teknik konseling ada yang bertujuan menjamin kelangsungan wawancara; ada pula yang bertujuan memberikan bantuan pada siswa dalam berpikimya atau memberikan pengarahan terbadap isi pikiran.Teknik-teknik yang digunakan ada yang disebut teknik umum dan khusus. Teknik umum terbuka untuk dipakai bahkan sebagian besar di antaranya harus diterapkan dalam melayani semua jenis kelien dengan aneka masalah mereka/ Variasi penggunaan teknik mumum sangat tergantung pada dinamika 
perkembangn proses layanan dan konten khusus yang direncanakan. Misalnya pertanyaan terbuka, refleksi isi dan perasaan, penyimpulan, konfrontasi.

Teknik khusus dilakukan untuk membina kemampuan tertentu pada diri klien. Misalnya teknik pemberian informasi, pemberian contoh dan latihan bertingkah laku, pemberian contoh pribadi, perumusan tujuan, desensitisasi, kursi kosong. Teknik khusus pemberian nasehat, mudah diucapkan, enak didengar, layak diiyakan tetapi tidak ada jaminan untuk keterlaksanaannya. Dalam konseling individual penggunaan nasihat sedapat-dapatnya dihindarkan, kecuali benar-benar diminta atau dibutuhkan klien.

Interaksi klien-konselor pada umumnya diselenggarakan melalui pembicaraan (dialog verbal). Konselor tidak boleh mendominasi pembicaraan klien. Pembicaraan ditekankan pada pentingnya klien memahami, merasakan, memikirkan, mempersepsi, mengukur wawasan sikap, mensinergikan berbagai hal dalam dirinya apa yang menjadi konten pembicaraan.Konseling individual dapat diselenggarakan kapan saja, di manapun juga. Hal ini memperhatikan kenyamanan dan diterapkannya asas kerahasiaan secara ketat. Kapan layanan konseling individual diselenggarakan atas kesepakatan kedua belah pihak, klien dan konselor.

\section{Sejarah Konseling Lintas Budaya}

Gladding (2012:100) menguraikan sejarah memberikan layanan konseling untuk populasi dengan budaya tertentu awalnya tidaklah populer. Fokus konseling multikultural secara kronologis ditekankan pada klien pada era 1950an, pada konselor di era 1960an, kemudian pada proses konseling itu sendiri secara total di era 1970 hingga saat ini. Pada akhir 1980an konseling lintas budaya menjadi salah satu topik terhangat dalam profesi konselor ditandai dengan peningkatan signifikan dari jurnal konseling yang bertemakan isu lintas budaya di abad ke 21 ini. Sejak tahun 1972 bahkan sudah ada Association for Multicultural Counseling and Development (disingkat AMCD) yang menjadi lembaga untuk mendefenisikan dan berurusan dengan isu-isu dan kepedulian yang berhubungan dengan konseling lintas budaya (di Amerika Serikat). Hingga saat ini AMCD mensponsori pelatihan untuk membantu konselor menguasai Multicultural Competence Standar yaitu kemampuan yang mengukur sejauh apa konselor memiliki tingkat kesadaran diri, pengetahuan, dan keterampilan yang akurat dalam bekerja dengan individu dari latar belakang budaya yang berbeda-beda (Constantine et al, 2007 dalam Glading, 20012).

\section{METODOLOGI}

Penelitian ini menggunakan pendekatan kualitatif yaitu jenis library research. Ciri utama library research menurut Mustika Zed (2004) yaitu peneliti menemukan teks (nash) atau data angka dan bukan dengan pengetahuan langsung dari lapangan atau saksi mata (eyewitness)berupa kejadian,orang atau benda-benda lainnya. Kelebihan penelitian studi kepustakaan adalah mengandalkan data yang ada dari buku-buku dan pendapat expert yang sudah tersedia di perpustakaan. Dengan demikian peneliti memperoleh bahan dari second responden dan bukan data orisinil dari tangan pertama di lapangan. Kelebihan lainnya adalah library researchtidak dibatasi oleh ruang dan waktu. Peneliti menganalisis rumusan masalah berdasarkan literatur yang ada dan mengambil kesimpulan guna mencapai tujuan penelitian.

\section{TEMUAN}

Berdasarkan riset kepustakaan tentang miskonsepsi budaya dalam melakukan konseling dapat digambarkan bahwasesungguhnya masih terdapat perbedaan para ahli konseling tentang aspek budaya dalam konseling. Menurut Gladding (2012:100) ada kelompok etic perspektif dimana para ahli berpendapat kualitas universal dalam konseling dapat digeneralisasikan pada semua 


\section{MEWASPADAI MISKONSEPSI NILAI BUDAYA DALAM PELAKSANAAN KONSELING INDIVIDUAL}

kebudayaan. Disisi lain ada kelompok dengan pendekatan emic perspective yaitu pandangan ahli bahwa pendekatan konseling haruslah didisain secara spesifik untuk masing-masing budaya.

Kenyataannya unsur budaya yang ada pada diri klien dan terjadi dalam proses konseling sangat sensitif dan perlu diwaspadai adanya kekeliruan konsep konselor dalam memahaminya. Berikut diuraikan beberapa miskonsepsi nilai budaya dalam konseling :

\section{Culturally encapsulated}

Kekuatan nilai-nilai kebudayaan sendiri, pada umumnya, tidak disadari satu anggota masyarakat seperti seorang klien, tetapi kekuatan dan pengaruhnya sangat dominan, bukan saja terhadap tingkah laku atau perangai individu anggota masyarakat bersangkutan, tetapi juga terhadap pandangan hidup anggota masyarakat itu terhadap budaya lain. Menurut Zais (1976) hal ini disebut unconscious culturally induced bias. Taba (1962:52) menyebutnya ethnocentricity atau culturally boundness dan Royce menamakan encapsulation, yaitu kondisi umum manusia yang yakin tentang kebenaran persepsinya atas suatu realita, pada hal, oleh karena beberapa keterbatasan, dia hanya memiliki gambaran yang tidak benar, tidak lengkap atau tidak akurat tentang realita yang sebenarnya (Zais,1976:219).

Maka kata enkapsulasi dapat dipahami seperti pepatah mengatakan ibarat'katak dibawah tempurung". Katak yang setiap hari hanya berada dibawah tempurung sudah melihat bahwa dunia itu luas seluas tempurung yang ditempatinya. Padahal diluar sana ketika tempurungnya dibuka, dan dia mengenalnya lebih jauh maka kehidupannya tidak semata benar menurut persepsinya selama ini. Jadi jika kita lihat perumpaan ini pada suatu masyarakat, maka mereka merasa benar dengan kebudayaannya sendiri, tidak melihat bahwa budaya orang lain lebih baik, atau bahkan menganggap remeh dan tidak mau belajar dari kelebihan yang dimiliki oleh masyarakat lain yang lebih maju. Itulah yang dimaksud dengan enkapsulasi.

Faktor penyebab terjadinya encapsulated ini menurut Zais (1976:219-29) adalah:

\section{Keterbatasan Fisiologis Manusia}

Moh Ansyar (2014) menguraikan secara genetika dan fisiologis, manusia dibatasi kemampuan untuk melihat dunia sekelilingnya. Umpama, manusia hanya mampu mendengar suara antara 2020.000 saikel per detik; di luar skala ini manusia tidak mendengar apa-apa. Kemampuan melihat hanya $1 / 70$ dari keseluruhan panjang gelombang cahaya. Sedangkan kemampuan cium dan mencicip manusia sangat jelek. Selain itu, kemampuan manusia membedakan kadar penciuman (smells), pencicipan (tastes) sangat lemah, dan kemampuan perabaan (tactual sense), menurut Royse, tercatat sebagai salah satu kelemahan manusia (Zais, 1976:219). Oleh karena itu, manusia memandang dunia ini melalui seperangkat indera fisiologisnya yang tidak teapt walapun diyakini manusia sangat akurat, sehingga apa-apa yang dilihat, dirasa, dicicipi dan diraba manusia sebenarnya bukanlah suatu kebenaran, hanya benar menurut pandangan manusia saja. Faktor inilah yang menyebabkan kapsulasi fisiologis manusia.

Dalam analisis tentang keterbatasan fisiologis ini, kita dapat pahami bahwa hal yang kita pahami dan tingkahlaku, pola pikir kita terhadap sesuatu sebatas kebiasaan dan apa yang kita lihat, dengar, dan rasakan.Kecenderungan kita sudah merasa puas dan hebat, padahal diluar sana ada yang kita tidak ketahui lebih baik dari apa yang sudah kita perbuat.

\section{Keterbatasan Psikologis}

Banyak sekali fakta psikologis yang menimbulkan kapsulasi psikologis. Beberapa hal yang sangat penting (dalam Zais,1976: 220) adalah: Kemampuan manusia untuk belajar dan berpikir sangat terbatas. Umpamanya, seperti yang dikemukakan Royce (dalam Zais, 1976 hal 220), daya ingat manusia sangat terbatas sehingga lupa sangat cepat dari pada mengingat. Sebagian besar orang tidak dapat mengulang 10 angka yang telah didiktekan kepada mereka, kemampuan manusia 
mengkonsepsikan ide-ide yang abstrak dan mengaitkan ide-ide tersebut sangat terbatas, seperti banyaknya orang yang lemah memahami konsep-konsep abstrak seperti terdapat dalam mata pelajaran matematika, dan kesulitan banyak orang untuk memahami metafor yang terdapat dalam karya-karya susastera, banyak orang yang berpikir irasional, walau berpikir rasional merupakan "merek"nya manusia saja, dan tidak dimiliki oleh makluk lain.

Contohnya konsep seperti rasa bersalah pada diri individu berbeda pada satu kelompok masyarakat dengan kelompok masyarakat lain. Orang di Asia Timur dalam penelitian Azzuma (1988 dalam dalam Uichol Kim, 2010: 19) memiliki rasa bersalah atau merasa berutang kepada orang tua merupakan satu bentuk pengabdian, sikap memanjakan, pengorbanan dan cinta seorang anak pada orang tua. Anak- anak merasa berutang budi karena mereka tidak dapat membalas cinta dan perhatian yang mereka terima dari orang tuanya. Rasa bersalah di Asia Timur dianggap sebagai emosi interpersonal penting yang mendukung sikap berbakti kepada orang tua, motivasi berprestasi dan kedekatan. Sementara dalam teori psikoanalitik dan psikologi barat, rasa bersalah diduga berdasarkan pada keyakinan yang irasional, ketakutan yang tidak realistis, keinginankeinginan yang terlarang. Ketika konselor berhadapan dengan remaja dari Asia Timur dan dari negara Barat mereka harus melihat konsep rasa bersalah yang berbeda.

Pada proses konseling Gilber Wern (1962) dalam Gladding (2012:101) menjelaskan, culturally encapsulated counselor dimaknai sebagai orang yang tidak menghormati perbedaan budaya dan bekerja dibawah asumsi yang salah bahwa teori dan teknik bisa dipalikasikan secara sama pada semua orang. Konselor semacam ini tidak sensitif terhadap pengalaman aktual klien dari latar belakang budaya, ras, dan etnik yang berbeda-beda dan olek karena itu mereka bisa mendiskriminasikan sejumlah orang denga memperlakukan semua klien sama.

\section{Overculturalizing}

Overculturalizing yaitu salah menanggapi reaksi masyarakat terhadap kemiskinan dan diskriminasi sebagai pola kultural (Smith dan Vasques, dalam Gladding, 2012:102). Konselor semacam ini tidak bisa memisahkan perbedaan yang muncul karena perbedaan latar belakang budaya dengan perbedaan yang disebabkan oleh kemiskinan atau status tertekan. Kasus imigran, penduduk minoritas, penggunaan bahasa ibu dari klien yang tidak dipahami konselor, menjadi contohcontoh overculturalizing ini. Konselor yang berasal dari budaya minoritas dapat terjebak dengan perasaan dendam "korban sejarah" baik sadar maupun tidak sadar terhadap budaya mayoritas yang dimiliki klien. Sebaliknya konselor yang berasal dari budaya mayoritas mungkin membawa sikap superior dan merasa lebih istimewa.

\section{Rasisme}

Rasisme merupakan prasangka yang ditunjukkan secara gamblang akibat mengenali atau mempersepsi perbedaan latar belakang fisik maupun psikologis suatu kelompok (Gladding, 2012:102). Rasisme memandang rendah semua yang berpartisipasi dalam kelompok tersebut. Bentuk perilaku konselor yang mengandung rasisme adalah ketidakpedulian atau ketakutan pada satu kelompok klien dengan latar belakang tertentu. Misalnya suku Batak yang terkenal keras diabaikan atau dianggap pantas mendapatkan masalah karena perilakunya yang kasar, dalam konsep seorang konselor yang berasal dari suku Jawa.

\section{Akulturasi}

Akulturasi adalah suatu proses dimana sekelompok masyarakat meninggalkan cara yang lama dan mengadopsi cara baru (Romero, 1989 dalam Gladding 2012). Artinya klien yang sedang mengalami akulturasi adalah mengadopsi cara baru dalam kehidupannya, dimana ini tidaklah pekerjaan yang mudah. Seperti klien yang pindah keyakinan atau agama, maka ia akan mengalami kesulitan-kesulitan diawal seperti benturan budaya lama, penolakan dari orang-orang disekitarnya, 


\section{MEWASPADAI MISKONSEPSI NILAI BUDAYA DALAM PELAKSANAAN KONSELING INDIVIDUAL}

stress psikologis, rasa bersalah, apatis, deprsi, rasa marah, percaya diri yang rendah. Konselor yang menangani klien yang sedang mengalami akulturasi ini sangat penting mengetahui sejauhmana keadaan kliennya. Weinrach \& Thomas (dalam Gladding, 2012) menegaskan konselor perlu memahami posisi klien dalam proses akulturasi yang berkesinambungan agar dapat memberikan pelayanan yang tepat. Konselor yang tidak melakukan hal ini akan mengalami miskonsepsi tentang budaya klien.

\section{DISKUSI}

Konselor yang waspada akan terjadinya miskonsepsi nilai budaya klien perlu memiliki keyakinan bahwa teori-teori, dan teknik konseling tidak bisa digeneralisasi untuk semua klien dari budaya yang berbeda. Menurut Bandura (1997, dalam Uichol Kim, 2010: 18), kewaspadaan konselor ini dimungkinkan karena pada dasarnya manusia memiliki kemampuan atau kapasitas untuk menelaah nilai-nilai, keyakinan, dan keterampilannya dan kapabilitas untuk mengubah dirinya, orang lain dan budaya.

Selanjutnya Pederson (1987 dalam Gladding, 2012:103) menegaskan konselor perlu mencermati fakta dan realita diri klien sedalam-dalamnya agar tidak terjadi bias dan kegagalan dalam relasi konselor-klien saat proses konseling berlangsung. Oleh sebab itu konselor dituntut memiliki sensitifitas pada isu budaya diri klien meliputi : (a) pengetahuan akan cara pandang klien yang berbeda budaya, (b) kepekaan terhadap cara pandang pribadi seseorang dan bagaimana ia merupakan produk dari pengkondisian budaya dan (c) keahlian yang diperlukan untuk bekerja dengan klien yang berbeda budaya.

Pederson (1987 dalam Gladding, 2012:103) mengembangkan model segitiga untuk membantu konselor mencapai pengertian yang lebih mendalam terhadap budaya secara umum dari penjelasannya diatas. Empat area dari model segitiga ini adalah (a) konselor harus memandang masalah dari perspektif budaya klien, (b) mengantisipasi perlawanan klien yang berbeda budaya, (c) mereduksi sikap melawan dengan cara mempelajari respons perlawanan pribadi, dan (d) mempelajari kemampuan untuk memulihkan untuk keluar dari kesulitan ketika mengkonselingi orang yang berbeda budaya.

Model lain yang menyesuaikan dengan perkembangan budaya global diantaranya model McFadden. Model ini memiliki keunggulan untuk membantu konselor melampaui batasan budaya dan mengatasi adanya bias teori-teori konseling yang terbatas secara budaya. Gladding (2012:105) menjelaskan model McFadden adalah perspektif lintas budaya yang berfokus pada tiga dimensi utama yang harus dikuasai oleh konselor yaitu :

a. Kultural-historikal, yakni konselor harus menguasai pengetahun akan budaya klien.

b. Psikososial, yakni konselor harus memahami etnik, ras, performa, percakapan, tingkah laku kelompok sosial dari klien agar bisa memiliki komunikasi yang bermakna

c. Saintifik-ideologi, yakni konselor harus menggunakan pendekatan konseling yang tepat untuk menghadapi masalah yang terkait dengan lingkungan regional, nasional dan internasional.

Tantangan globalisis dimana tidak ada sekat dan pembatas terjadinya akulturasi, adaptasi dan perbauran budaya membuat konselor harus mampu menerapkan model McFadden ini. Untuk itu kurikulum bagi calon konselor perlu mengakomodir dipelajarinya ketiga aspek ini sehingga menjadi bekal bagi konselor dalam melaksanakan konseling lintas budaya.

Pekerjaan konselor berhadapan dengan klien yang berbeda budaya, menjadi satu perhatian khusus dan kewaspadaan agar tidak terjadi bias dan miskonsepsi yang mewarnai relasi konselorklien dalam proses konseling. Atkinson (2004) menekankan bagaimanapun juga seorang konselor dituntut untuk peka terhadap latarbelakang klien dan kebutuhan khususnya, serta secara seimbang menyesuaikan diri dengan konsep nilai, bias, dan kemampuan klien. Jika tidak maka klien akan 
merasakan pengalaman traumatis dalam konseling dan tidak lagi mau mengikuti proses konseling berikutnya.

Untuk bisa memahami budaya klien, seorang konselor dituntut harus mampu mengembangkan kesadaran dirinya sendiri terlebih dahulu (self awareness of other). Gladding (2012:98) menyatakan oleh sebab itu seorang konselor harus menjadi pembelajar seumur hidup dan pengimplementasi metode bekerja dengan orang-orang berbeda budaya yang baru dan efektif.

\section{REFERENSI}

Belkin, Gary S. 1975. Practical Counseling in the School. USA: Wm. C. Brown Company Publishers. h. 456

Gibson, R.L. \& Mitchell, M.H. 1995. Introduction to Guidance. New York: Macmillan Publisher Mestika Zed. 2004. Metode Penelitian. Jakarta: Yayasan Obor Indonesia.

Moh.Ansyar. 2014. Analisis dan Perkembangan Kurikulum . Padang: UNP

Palmer, Stephen., McMahon, Gladeana. 1989. Handbook of counseling. Routledge: London and Newyork.

Prayitno dan Erman Amti. 2004. Dasar-Dasar Bimbingan Konseling. Cetakan ke dua.

Prayitno. 1994. Dasar-dasar BK (Buku II), Padang, PPB FIP IKIP Padang.

Syahril dan Riska Ahmad (1986). Pengantar Bimbingan dan Konseling. Padang: Angkasa Raya

Uichol Kim. 2010. Indigenous and Cultural Psychology Memahami orang dalam konteksnya. Yogyakarta: Pustaka Pelajar.

Vacc, Nicholas A.,Susan B.DeVaneyJohnston M.Brendel. 2003. Counseling Multiculturaland Diverse Populations: Strategies for Practitioners. New York: Routledge..

WS.Winkel. 1985. Bimbingan dan Konseling di Sekolah Menengah. Jakarta: Penerbit PT.Gramedia

Zais, Robert S. 1976. Curriculum; Principles and Foundations. Kent State University. 